\title{
Expression of anti-Mullerian hormone receptor on the appendix testis in connection with urological disorders
}

\author{
Kornél Kistamás ${ }^{1}$, Olga Ruzsnavszky ${ }^{1}$, Andrea Telek ${ }^{1}$, Lívia Kosztka ${ }^{2}$, Ilona Kovács ${ }^{2}$, Beatrix Dienes ${ }^{1}$, \\ László Csernoch ${ }^{1}$ and Tamás Józsa ${ }^{3,4}$
}

The female internal sex organs develop from the paramesonephric (Mullerian) duct. In male embryos, the regression of the Mullerian duct is caused by the anti-Mullerian hormone (AMH), which plays an important role in the process of testicular descent. The physiological remnant of the Mullerian duct in males is the appendix testis (AT). In our previous study, we presented evidence for the decreased incidence of AT in cryptorchidism with intraoperative surgery. In this report, the expression of the anti-Mullerian hormone receptor type 2 (AMHR2), the specific receptor of AMH, on the AT was investigated in connection with different urological disorders, such as hernia inguinalis, torsion of AT, cysta epididymis, varicocele, hydrocele testis and various forms of undescended testis. The correlation between the age of the patients and the expression of the AMHR2 was also examined. Reverse transcriptase-polymerase chain reaction (RT-PCR) and immunohistochemistry were used to detect the receptor's mRNA and protein levels, respectively. We demonstrate that AMHR2 is expressed in the ATs. Additionally, the presence of this receptor was proven at the mRNA and protein levels. The expression pattern of the receptor correlated with neither the examined urological disorders nor the age of the patients; therefore, the function of the AT remains obscure.

Asian Journal of Andrology (2013) 15, 400-403; doi:10.1038/aja.2012.135; published online 7 January 2013

Keywords: anti-Mullerian hormone receptor (AMHR); appendix testis (AT); hernia inguinalis; retention testis; testicular descent; testis retractile

\section{INTRODUCTION}

The female internal sex organs-oviducts, uterine horns, cervix and the anterior vagina-develop from the paramesonephric (Mullerian) duct. In male embryos, during embryonic development, the regression of the Mullerian duct is caused by the anti-Mullerian hormone $(\mathrm{AMH})$ /substance. According to recent theories, the abdominal part of the testicular descent is controlled by the $\mathrm{AMH},{ }^{1}$ and the absence of or genetic abnormalities in AMH or its receptors lead to the development of persistent Mullerian duct syndrome and cryptorchidism by preventing normal testicular descent. ${ }^{2,3}$ The vestigial remnant of the Mullerian duct is called the appendix testis (AT; hydatid of Morgagni) and is located at the upper pole of the testis or in the groove between the testis and the epididymis. ${ }^{4}$ The incidence of AT is reported as being between $76 \%$ and $92 \%,{ }^{5,6}$ but this rate is decreased in cryptorchidism, ${ }^{5}$ suggesting a possible role of AT in the complex of testicular descent. AT is a structural unit that contains gelatinous vascular connective tissue stroma covered by Mullerian-type epithelium with subepithelial capillaries and lymphoid vessels. We do not know if it has any physiological function; currently, the known clinical importance of AT is that its torsion causes acute scrotum, and tumours can develop from it.

The cremaster muscle is a striated muscle with some differences from other skeletal muscles, such as its firing frequency and involuntary control. $^{7}$ A recent theory of testicular descent suggests the role of sympathetic nerves, which innervate the gubernacular smooth and striated muscles. ${ }^{8,9}$ In mice, AMH is not essential for gubernacular development or testicular descent, although it is important in determining the thickness of the cremaster muscle. ${ }^{10}$

There is no information on the expression of anti-Mullerian hormone receptor type 2 (AMHR2) in AT, although it is possible that the cells of AT express this receptor during embryonic development and most likely after birth as well. Torsion of the AT is painful, and patients with this condition show similar symptoms to those with torsion of the testis. Therefore, removal of the AT is medically indicated when it appears during intrascrotal operations. ${ }^{11}$ Appendices from such operations were used in our research as well as specimens of the cremaster muscle. The relationship between several urological diseases and the expression of AMHR2, the specific receptor for AMH, in ATs was investigated in this study.

\section{MATERIALS AND METHODS}

Collection of the samples

A total of 109 ATs and nine cremaster muscles were collected from male patients undergoing surgical exploration at the Surgical Ward of the Department of Pediatrics, Medical and Health Science Center, University of Debrecen, Debrecen, Hungary. The study protocol was 
approved by the Human Ethics Committee of Medical and Health Science Center, University of Debrecen. Written informed consent was obtained from the parents or guardians before the children entered the study. The samples used for the polymerase chain reaction (PCR) experiments were collected from patients suffering from the following diseases: hernia inguinalis, torsion of AT, cysta epididymis, varicocele, ectopic testis, testis retractile, retention testis and hydrocele. The samples used for the immunohistochemistry experiments were obtained from patients suffering from the following diseases: hydrocele, retention testis, varicocele, cysta epididymis and hernia inguinalis.

\section{Immunohistochemistry}

For immunohistochemistry, 4- $\mu \mathrm{m}$ thick, formalin-fixed sections were used. First, the sections were rehydrated $(4 \times 5 \mathrm{~min}$ xilol and $4 \times 1 \mathrm{~min}$ ethanol), and to uncover the antigens, the sections were boiled in citrate buffer $\left(2 \mathrm{~min}, 0.1 \mathrm{~mol} \mathrm{l}^{-1}, \mathrm{pH}=6.0\right)$. The activity of endogenous peroxidases was inhibited with hydrogen peroxide $(10 \mathrm{~min}$, $3 \%)$. Next, the nonspecific binding sites were blocked with $2.5 \%$ horse serum (20 $\mathrm{min}$, room temperature, ImmPRESS kit; Vector Laboratories, Burlingame, CA, USA). Then, the AMHR2-specific primary antibody (diluted in phosphate-buffered saline containing $1 \%$ bovine serum albumin, produced in mouse; AbCam, Cambridge, UK) was used in a 1:300 dilution (final concentration $6.7 \mu \mathrm{g} \mathrm{ml}^{-1}$ ). After washing the sections (phosphate-buffered saline, $3 \times 5 \mathrm{~min}$ ), they were incubated with horseradish peroxidase-conjugated secondary antibody ( $30 \mathrm{~min}$, room temperature, ImmPRESS kit; final concentration $1 \mu \mathrm{g} \mathrm{ml}^{-1}$ ), and then the sections were washed again (phosphate-buffered saline, $3 \times 5 \mathrm{~min}$ ). The reaction was visualized by ImmPACT DAB kit (Vector Laboratories), according to the manufacturer's protocol. Nuclei were revealed by haematoxylin (10 s), and sections were dehydrated $(2 \times 1 \mathrm{~min}$ ethanol, $3 \times 1 \mathrm{~min}$ acetone and $2 \times 1 \mathrm{~min}$ xilol) before being covered by Shandon Consul Mount medium (Thermo Scientific, Budapest, Hungary). Endometrium sections were used as a positive control. Negative controls were made by omitting the primary antibody.

\section{Reverse transcriptase-polymerase chain reaction (RT-PCR) analysis}

For RT-PCR analysis, samples were stored in RNAlater (Ambion; Life Technologies, Budapest, Hungary) at $-70^{\circ} \mathrm{C}$. Total ribonucleic acid (RNA) was isolated from tissues using TRIzol reagent (Invitrogen, Carlsbad, CA, USA). Tissues were sonicated in $1 \mathrm{ml}$ TRIzol (Invitrogen) reagent $(3 \times 10 \mathrm{~s})$, and then $0.2 \mathrm{ml}$ chloroform was added to the samples. Samples were mixed well and centrifuged $(12000 \mathrm{~g}, 15 \mathrm{~min}$, $4{ }^{\circ} \mathrm{C}$ ). The upper, colourless phase, which contains the RNA, was used. It was then gently mixed with $0.5 \mathrm{ml}$ isopropanol and incubated for $1 \mathrm{~h}$ at $-20^{\circ} \mathrm{C}$ and centrifuged again $\left(12000 \mathrm{~g}, 10 \mathrm{~min}, 4^{\circ} \mathrm{C}\right)$. The sediment was washed with $75 \%$ ethanol and dissolved in nuclease-free water. The assay mixture $(20 \mu \mathrm{l})$ for the reverse transcriptase reaction (Omniscript; Qiagen, Budapest, Hungary) contained 500 ng RNA, $0.25 \mu \mathrm{l}$ RNase inhibitor, $0.25 \mu \mathrm{l}$ oligo(dT), $1 \mu \mathrm{ldNTP}\left(200 \mu \mathrm{mol} \mathrm{ml}^{-1}\right)$ and $1 \mu \mathrm{l}$ M-MLV RT in $1 \times$ RT buffer.

Amplifications of specific complementary deoxyribonucleic acid sequences were performed with specific primers. PCR reactions were allowed to proceed in a final volume of $50 \mu \mathrm{l}$ (containing $1 \mu \mathrm{l}$ each of forward and reverse primers, $1 \mu \mathrm{ldNTP}\left[200 \mu \mathrm{mol} 1^{-1}\right]$, and $5 \mathrm{U}$ Promega GoTaq DNA polymerase in $1 \times$ reaction buffer) in a programmable thermocycler (Eppendorf Mastercycle, Netheler; Hinz $\mathrm{GmbH}$, Hamburg, Germany) with the following settings: 2 min at $95^{\circ} \mathrm{C}$ for initial denaturation followed by repeated cycles of denaturation at $94^{\circ} \mathrm{C}$ for $1 \mathrm{~min}$, primer annealing for $60 \mathrm{~s}$ at an optimized temperature, and extension at $72^{\circ} \mathrm{C}$ for $1 \mathrm{~min} 30 \mathrm{~s}$. After the final cycle, further extension was allowed to proceed for another $10 \mathrm{~min}$ at $72^{\circ} \mathrm{C}$. PCR products were analysed using a $1.5 \%$ agarose gel. EZVision (Amresco, Solon, OH, USA) was used as loading dye and the results were observed in UV light. Densitometry analysis was performed using Image J software (Wayne Rasband; National Institutes of Health, Bethesda, MD, USA). Together with the anti-Mullerian hormone receptor (AMHR), glyceraldehyde-3-phosphate dehydrogenase mRNA expression was also determined and used as an internal control.

\section{Primer design}

The specific primers (Integrated DNA Technologies, Coralville, IA, USA) were designed based on published nucleotide sequences. Primers were designed using the NCBI (National Center for Biotechnology Information), Primer Premier software (PREMIER Biosoft International, Palo Alto, CA, USA) and the NCBI PrimerBLAST program (Basic Local Alignment Search Tool). Primers were screened for secondary structures, hairpins, dimers, homologies and physical properties.

The sequences of the primer pairs were as follows:

Glyceraldehyde-3-phosphate dehydrogenase: forward 5'-AAGGTCGGAGTCAACGGATTTGG-3', reverse 5'-AATGAGCCCCAGCCTTCTCCAT-3'; AMHR2: forward 5'-TCGGGAAGATGGATCGTGT-3', reverse $5^{\prime}$-GGAAGGGTGGTGGACTGCT- ${ }^{\prime}$.

\section{Statistical methods}

Statistical analysis was performed using SigmaStat software (Aspire Software International, Ashburn, VA, USA). Most of the observed data failed to show a normal distribution $(P<0.05)$; therefore, non-parametric tests (Spearman correlation coefficient) were used to assess agedependent correlations. The expression of AMHR2 was evaluated using Fisher's exact test to determine if there were nonrandom associations between two disease types.

\section{RESULTS}

ATs and pieces of cremaster muscles were collected from patients suffering from various urological diseases. The mRNA expression of AMHR2 in these samples was determined using RT-PCR. Glyceraldehyde-3-phosphate dehydrogenase was used as an internal control. For ATs, in patients with retractile testis $(n=9)$, the mRNA of the receptor was detected in only one sample $(11 \%)$, whereas in patients with torsion of AT $(n=3)$ and cysta epididymis $(n=1)$, most of the samples $(67 \%$ and $100 \%$, respectively) were positive. The mRNA of the AMHR2 was not detectable in the ATs from the patients suffering from ectopic testis and varicocele $(n=2$ and $n=1$, respectively). In the samples of hernia inguinalis $(n=14)$, the mRNA of the receptor was shown in $50 \%$ of the samples, whereas in the case of hydrocele testis $(n=13)$, only $15 \%$ of the samples were positive for the mRNA of the receptor. In the samples with retention testis $(n=17)$, the mRNA was present in $35 \%$ of the ATs (Figure 1a). Statistical calculation did not show any association between the positivity under different circumstances $(P>0.05)$.

The protein level expression of AMHR2 was demonstrated by immunohistochemistry. The presence of the receptor was observed in the interstitium of the AT in immunohistochemistry sections (Figure 2). The protein of the receptor was detectable in $25 \%$ of the samples of patients with cysta epididymis $(n=12)$, in $67 \%$ of the samples of hernia inguinalis $(n=6)$, in $64 \%$ of the samples of hydrocele 


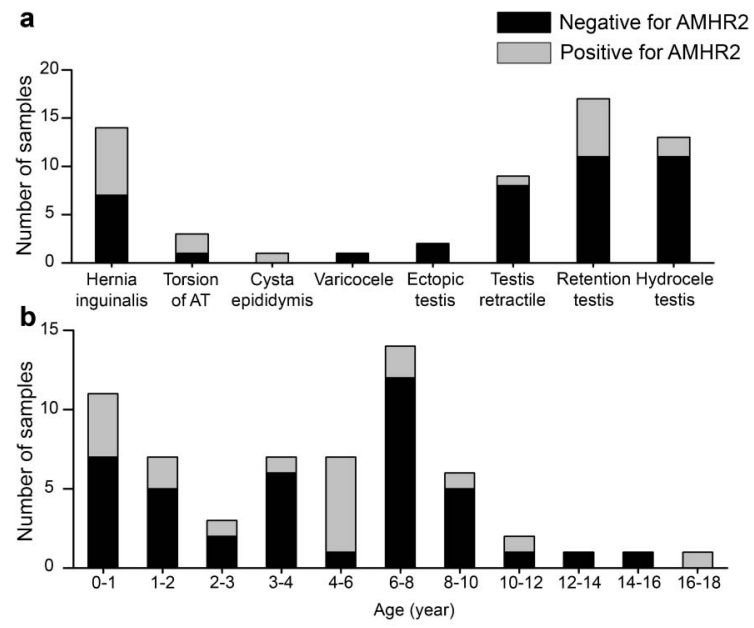

Figure 1 Detection of AMHR2 mRNA with RT-PCR on ATs $(n=60)$. (a) The age dependence of the appearance of AMHR2 mRNA in the AT. (b) The appearance of mRNA of AMHR2 in different urological disorders. AMHR2, anti-Mullerian hormone receptor type 2; AT, appendix testis; RT-PCR, reverse transcriptasepolymerase chain reaction.

testis $(n=25)$ and in $100 \%$ of the samples of retention testis $(n=3)$. In cases of varicocele $(n=3)$, the protein of AMHR2 was shown in only one sample (33\%) (Figure 3a). No association was shown by statistical tests $(P>0.05)$.

The age dependence of the mRNA and protein expression of AMHR2 in AT was also investigated by Spearman's correlation coefficient. No correlation was found between the ages of the patients and the mRNA expression of this receptor $(P>0.05)$ (Figure 1b). In contrast, the protein level expression of AMHR2 did show some age dependence. Under the age of 12, i.e., before puberty, all of the AT samples expressed the AMHR2 protein. However, above the age of 12, there was no correlation between the presence of the AMHR2 and the age of the patients (Figure $\mathbf{3 b}$ ).

Investigations of the cremaster muscles showed that the mRNA of AMHR2 could not be detected in patients who suffered from hernia inguinalis $(n=3)$. In retention testis, one of the samples was positive for AMHR2, whereas the other was negative $(n=2)$. AMHR2 was detectable in three of the four samples of hydrocele testis $(n=4)$ (Figure 4).

\section{DISCUSSION}

AMH is secreted by immature Sertoli cells. The serum level of AMH stays high in males until puberty. ${ }^{12}$ Defects of the AMH and AMHR2 cause persistent Mullerian duct syndrome, ${ }^{2,13}$ where some of the internal females sex organs can be found in a male. AMH has been
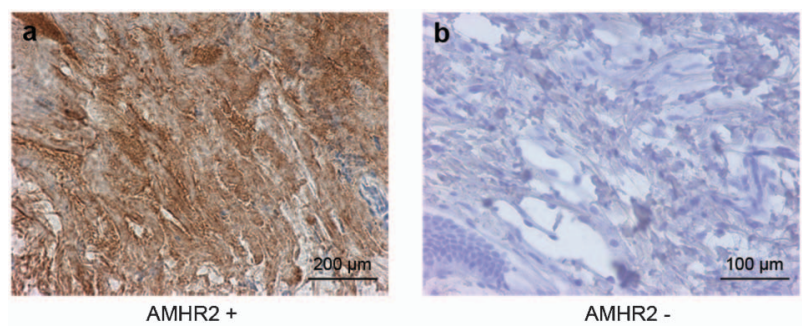

Figure 2 Visualisation of AMHR2 on paraffin-embedded 4- $\mu$ m thick sections. Brown staining (DAB) represents the AMHR2. Scale bar $=200 \mu \mathrm{m}$ (a) and $100 \mu \mathrm{m}$ (b). AMHR2, anti-Mullerian hormone receptor type 2; DAB, diaminobenzidine.

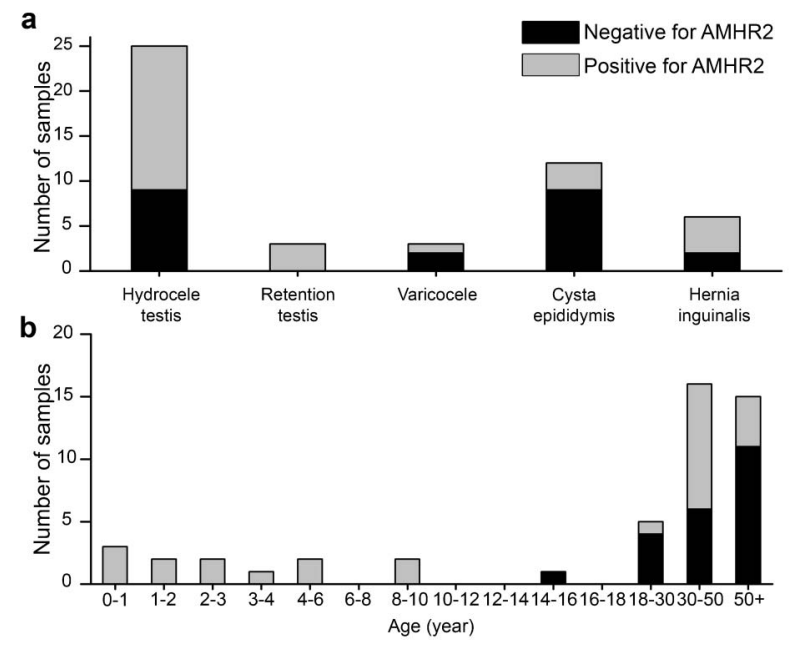

Figure 3 Detection of AMHR2 protein expression with immunohistochemistry $(n=49)$. On panel (a) the age dependence of the expression of AMHR2 in the AT was shown. (b) The expression of AMHR2 in different urological disorders. AMHR2, anti-Mullerian hormone receptor type 2; AT, appendix testis.

evaluated by several groups as a potential novel clinical marker for ovarian reserve. ${ }^{14}$ Serum AMH concentrations show a progressive decline with female ageing. ${ }^{14}$ Testicular AMH production increases in response to follicle-stimulating hormone and is potently inhibited by androgens. Serum AMH is undetectable in anorchid patients. In primary or central hypogonadism affecting the whole gonad established in fetal life or in childhood, all testicular markers are low. Conversely, when hypogonadism only affects Leydig cells, serum $\mathrm{AMH}$ is normal. In males of pubertal age with central hypogonadism, AMH is low. ${ }^{15}$ Recent studies show that the transabdominal phase of testicular descent is under the control of insulin-like peptide 3 and $\mathrm{AMH}$, and the studies assume a role for the cremaster muscle. ${ }^{16}$

The significantly lower presence of AT in patients with undescended testis ${ }^{5}$ suggests that AT might play a role in the process of testicular descent; therefore, the question arises as to whether a demonstrable relationship can be found between AMH receptor expression in AT in cryptorchidism compared with that of other peri-testicular disorders.

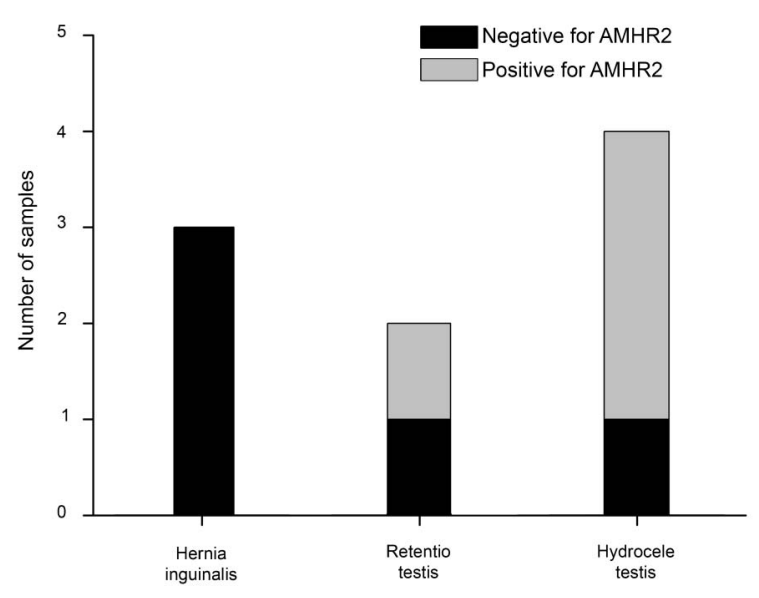

Figure 4 Detection of mRNA of AMHR2 with RT-PCR on cremaster muscles in connection with different urological disorders $(n=9)$. AMHR2, anti-Mullerian hormone receptor type 2; AT, appendix testis; RT-PCR, reverse transcriptasepolymerase chain reaction. 
Furthermore, it is likely that the cells of AT express the AMHR2; however, there was no information about the expression of AMHR2 in AT.

For the first time, we have shown that both the mRNA and the protein of the AMHR2 are detectable in the AT. Although the mRNA of AMHR2 was present in several samples, the lack of mRNA expression of the receptor did not show any relationship with the most common urological disorders, such as the hernia inguinalis, retention testis or hydrocele testis. Although the results from patients with retractile testis seemed to indicate a connection between the lack of AMHR2 and the development of this urological disorder, it is, nevertheless, believed to be due to statistical fluctuation, because in related pathological circumstances (retention testis and hernia inguinalis), there were no similar observations.

Samnakay et al. ${ }^{17}$ found that rising levels of androgens and oestrogens in pubertal boys may account for enlargement and the predisposition of the human AT to torsion because this structure contains receptors for both. In our study, we examined the possible role of $\mathrm{AMH}$ in this process and found that the mRNA of this receptor is present in most of the samples of the torsion of AT and cysta epididymis, although the number of samples was quite low. In the examined samples obtained from patients with various urological diseases, the mRNA and protein levels showed diverse expression patterns. This observation strengthens the suggestion that the prevalence of AT is incidental in postnatal life. ${ }^{18}$

There was also no correlation between the mRNA expression of the AMHR2 and the age of the patients. We found some correspondence between the protein expression of AMHR2 and the patients' ages-all patients younger than 12 years expressed the AMHR2 in their AT; however, the PCR results unfortunately did not show the same relationship. In the population over 12 years, we could not find any correlation between the expression pattern and age. The mRNA expression of AMHR2 in cremaster muscles also did not show any connection with the above-mentioned urological disorders.

The AMHR2 on AT was first detected by our research group. Our study did not reveal any connection between the expression of AMHR2 and undescended testis; therefore, our results did not prove any physiological function for AT. A variety of urological disorders were investigated to describe the function of the AMHR2 on AT. However, because elevated expression of mRNA and protein was found in particular diseases, the AMHR2 cannot be used as an unambiguous indicator of any examined urological disorder.

\section{AUTHOR CONTRIBUTIONS}

$\mathrm{TJ}$ and LC designed the project. KK, OR, AT and LK carried out the study and performed the preparation. KK, OR, BD, TJ and LC prepared the analysis of the data and interpretation. KK and OR drafted the manuscript. IK, BD, LC and TJ were involved in the study design and data management of the study. All authors provided critical revisions for the manuscript.

\section{COMPETING FINANCIAL INTERESTS}

The authors declare no competing financial interests.

\section{ACKNOWLEDGMENTS}

The authors are indebted to Ms Róza Őri and Ms Ibolya Kiss for their excellent technical assistance. This work was supported by the TÁMOP-4.2.1/B-09/1/ KONV-2010-0007 and the TÁMOP-4.2.2/B-10/1-2010-0024 projects. The project was cofinanced by the European Union and the European Social Fund.

1 Josso N. Antimullerian hormone: new perspectives for a sexist molecule. Endocr Rev 1986; 4: 421-33.

2 Josso N, Belville C, di Clemente N, Picard JY. AMH and AMH receptor defects in persistent Mullerian duct syndrome. Hum Reprod Update 2005; 11: 351-6.

3 Karnak I, Tanyel FC, Akçören Z, Hiçsönmez A. Transverse testicular ectopia with persistant müllerian duct syndrome. J Pediatr Surg 1997; 32: 1362-4.

4 Atkinson GO Jr, Patrick LE, Ball TI Jr, Stephenson CA, Broecker BH et al. The norma and abnormal scrotum in children: evaluation with color Doppler sonography. AJR Am J Roentgenol 1992; 158: 613-7.

5 Józsa T, Csízy I, Kutasy B, Cserni T, Flaskó T. Decreased incidence of appendix testis in cryptorchidism with intraoperative survey. Urol Int 2008; 80: 317-20.

6 Rolnick D, Kawanoue S, Szanto P, Bush IM. Anatomical incidence of testicular appendages. J Urol 1968; 100: 755-6.

7 Kayalioglu G, Altay B, Uyaroglu FG, Bademkiran F, Uludag B et al. Morphology and innervation of the human cremaster muscle in relation to its function. Anat Rec (Hoboken) 2008; 291: 790-6.

8 Tanyel FC, Müftüoglu S, Dagdeviren A, Kaymaz FF, Büyükpamukçu N. Myofibroblasts defined by electron microscopy suggest the dedifferentiation of smooth muscle within the sac walls associated with congenital inguinal hernia. BJU Int 2001; 87: 251-5.

9 Tanyel FC. The descent of testis and reason for failed descent. Turk J Pediatr 2004 46: 7-17.

10 Bartlett JE, Lee SM, Mishina Y, Behringer RR, Yang N et al. Gubernacular development in Müllerian inhibiting substance receptor-deficient mice. BJU Int 2002; 89: 113-8.

11 Anderson PJ, Kincaid R, Orr JD. Testicular appendages: incidence and clinical significance. Pediatr Surg Int 1995; 10: 118-9.

12 Aksglaede L, Sørensen K, Boas M, Mouritsen A, Hagen CP et al. Changes in antiMüllerian hormone (AMH) throughout the life span: a population-based study of 1027 healthy males from birth (cord blood) to the age of 69 years. J Clin Endocrinol Metab 2010; 95: 5357-64.

13 Lane $\mathrm{AH}$, Donahoe PK. New insights into mullerian inhibiting substance and its mechanism of action. J Endocrinol 1998; 158: 1-6.

14 la Marca A, Spada E, Grisendi V, Argento C, Papaleo E et al. Normal serum antiMüllerian hormone levels in the general female population and the relationship with reproductive history. Eur J Obstet Gynecol Reprod Biol 2012; 163: 180-4.

15 Grinspon RP, Loreti N, Braslavsky D, Bedecarrás P, Ambao V et al. Sertoli cell markers in the diagnosis of paediatric male hypogonadism. J Pediatr Endocrinol Metab 2012; 25: 3-11.

16 Lie G, Hutson JM. The role of cremaster muscle in testicular descent in humans and animal models. Pediatr Surg Int 2011; 27: 1255-65.

17 Samnakay N, Cohen RJ, Orford J, King PA, Davies RJ. Androgen and oestrogen receptor status of the human appendix testis. Pediatr Surg Int 2003; 19: 520-4.

18 Jacob M, Barteczko K. Contribution to the origin and development of the appendices of the testis and epididymis in humans. Anat Embryol 2005; 209: 287-302. 